\title{
Comparative Study of the Combined Effect of Therapeutic Exercises and Mobilization between Stage II and Stage III Frozen Shoulder
}

\author{
OLA I. IBRAHIM, M.Sc. ${ }^{1}$; SALWA F. ABDEL-MAJID, Ph.D. ${ }^{2}$; WALID R. MOHAMED, Ph.D. ${ }^{3}$ and \\ MOHAMED A. SARHAN, Ph.D. ${ }^{4}$ \\ The Department of Physical Therapy for Orthopedics, Faculty of Physical Therapy, Cairo ${ }^{\mathbf{1}}{ }^{2}$ and \\ South Valley ${ }^{3}$ Universities and The Department of Orthopedic Surgery, Faculty of Medicine, Cairo University ${ }^{4}$, Egypt
}

\begin{abstract}
Background: It is clear that therapeutic exercise plus mobilization have significant benefits on range of motion in frozen shoulder however it is important to consider the patient's symptoms and the stage of the condition and suggest if the disease prognosis is affected by treatment.
\end{abstract}

Aim of Study: To compare the combined effect of shoulder mobilization and therapeutic exercises on pain, range of motion, and overall shoulder functions between stage II and stage III frozen shoulder.

Material and Methods: Thirty patients referred as frozen shoulder, were divided according to their stage of illness equally into two groups; group A (stage II) and group B (stage III). Both groups were treated with mobilization, stretching exercises, active exercise and Codman pendulum exercises and that was 2 times per week for successive two months. Each patient was assessed for shoulder ROM using universal goniometer pretreatment, post 6 sessions and post treatment and pain and disability using shoulder pain and disability index (SPADI) pretreatment and post treatment.

Results: There was significant effect of mobilization and therapeutic exercises on pain and overall shoulder functions in both groups with more significant effect in group A compared with group B ( $p=0.0001)$. Also there was significant effect on shoulder ROM of flexion and abduction in group A compared with that of group B $(p=0.0001)$. But there was no significant difference in shoulder internal rotation and external ROM between both groups ( $p=0.8 \& p=0.12$ ). Whereas there was a significant increase in shoulder extension ROM of group B compared with that group A $(p=0.001)$.

Conclusion: The combined effect of mobilization and therapeutic exercises has significant effect on pain and overall shoulder functions in stage II frozen shoulder than stage III and a significant effect on shoulder ROM in both stages.

Key Words: Frozen shoulder-Mobilization - Therapeutic exercises.

Correspondence to: Dr. Ola I. Ibrahim, The Department of Physical Therapy for Orthopedics, Faculty of Physical Therapy, Cairo University

\section{Introduction}

FROZEN shoulder (FS) is, although known for more than a century, still an enigmatic and poorly defined shoulder disorder [1]. The American Shoulder and Elbow Society (ASES) resulted in a consensus definition of adhesive capsulitis of shoulder as follows: "a condition characterized by functional restriction of both active and passive shoulder motion for which radiographs of the glenohumeral joint are essentially unremarkable" [2]. The aetiology of FS is usually unknown. It is generally accepted that underlying FS is an inflammatory process of the synovial membrane, which is subsequently followed by a fibrotic reaction of the fibrous layer. There is still disagreement over whether or not the underlying pathology is an inflammatory process, but arthroscopy shows a hyperemic and swollen synovial membrane. The recent discovery of several cytokines in the joint capsule in patients with FS supports the inflammation theory [1]. Frozen shoulder has an incidence of $2 \%$ to $5 \%$ of the general population mostly between age 40 to 65 years old and mostly women $[3,4,5]$.

It is commonly believed that frozen shoulder is idiopathic, self-limiting syndrome divided into four consecutive stages lasting approximately 24 months in total [6] ; (1) Painful stage: Less than 3 months. (2) Freezing stage: Symptoms continue for 3-9 months. (3) Frozen stage: Symptoms persist for 9-14 months. (4) Thawing stage: Occurs between 15-24 months [7]. In stage II, known as the "freezing stage," symptoms have been present with chronic pain and progressive loss of range of motion. There is significant limitation of forward flexion, abduction, internal rotation, and external 
rotation. Examination after intra-articular injection of local anesthetic or scalene block reveals relief of pain with partial improvement in range of motion. The motion loss in stage II reflects a loss of capsular volume and a response to painful synovitis. In the "frozen stage" (stage III), patients experience minimal pain at night or rest (except at the end range of motion) but have significant shoulder stiffness. Range of motion remains unchanged when the patient is injected with local anesthetic or examined under anesthesia, secondary to a profound loss of capsular volume and fibrosis of the glenohumeral joint capsule [8] .

It was concluded that exercise therapy was critically important in the treatment of frozen shoulder [9]. The use of joint mobilization as a form of manual therapy is increasing, due to evidence supporting its effect in reducing pain and joint range-of-motion deficits [10,11]. Maitland's grade I,II \& grade III,IV mobilization were evaluated and the overall conclusion supports the use of Maitland's grade III \& IV techniques in the management of frozen shoulder [12,13]. This study compared the combined effect of shoulder mobilization and therapeutic exercises on pain, range of motion (ROM), and overall shoulder functions between stage II and stage III frozen shoulder.

\section{Material and Methods}

This study was conducted at outpatient clinic of physical therapy at El-Kasr El-Aini Hospital, Cairo University, Egypt, at the period from (October 2018 to September 2019). All participants gave written informed consent prior to participation in the study approved by Research Ethical Committee, Faculty of Physical Therapy, Cairo University (No:P.T.REC/012/002044). Study design is repeated measures design. Thirty patients ( 9 males and 21 females) with mean age of 53.5 years referred as frozen shoulder were distributed according to their stage of frozen shoulder equally into two groups, stage II (group A) and stage III (group B). The inclusion criteria were primary frozen shoulder stage II and stage III, global shoulder ROM restriction and pain for more than 3 months, normal shoulder radiographs, with exception of evidence of Osteopenia and one-sided shoulder involvement $[14,15]$. The exclusion criteria were secondary frozen shoulder, additional shoulder or cervical pathology, diabetes mellitus, infection, severe trauma or fracture, previous shoulder surgeries to the affected shoulder, shoulder girdle motor control deficits associated with neurological disorders (e.g. stroke, or Parkinson's disease), pregnancy, carci- noma patients, severe cardiac or psychiatric conditions, insertion of pace maker and any serious medical condition that would stop active contribution in the study $[\mathbf{1 4 , 1 5 ]}$.

\section{Instruments:}

Measuring equipment: Universal goniometer for measuring shoulder ROM (active and passive) and shoulder pain and disability index (SPADI) for measuring shoulder pain and overall function.

Therapeutic equipment: Hot packs for warming up, stick, belt and ice packs at the end of session for decreasing pain and discomfort.

\section{Intervention protocol:}

Assessment procedures were done pretreatment, after 6 sessions ( 3 weeks) and post treatment (2 months) for shoulder flexion, extension, abduction, internal and external rotations ROMs by using universal goniometer according to application of Norkin \& White (2016) [16]. Patients filled the questionnaire of shoulder pain and disability index pretreatment and post treatment. It contains 5 items assessing pain and 8 items assessing shoulder function. Each item is scored on visual analogue scale with (Right end) defined as "worst pain imaginable/so difficult required help", (Left end) "no pain/no difficulty". Patients signed on the VAS below each question and the score calculated using a ruler with (zero) end at right end of the VAS and (ten) end at left end of VAS [17]. All questions were added in part one pain scores and part two functional scores. Final score for each part was statistically analyzed separately.

Both groups received physical therapy program of 2 sessions per week for 2 months. Each session lasted 30-45 minutes including manual mobilization techniques grade II \& III \& general exercises. The program consisted of mobilization (Distraction in progressive positions, Lateral distraction, Inferior glide (Supine 90/90) and Posterior glide), stretching exercises (Posterior capsule stretch, Supine flexion stretch, Tabletop flexion stretch, Tabletop external rotation stretch, Horizontal adduction stretch, Horizontal adduction with internal rotation stretch, Reaching-behind-the-back stretch: Extension, Reaching-behind-the-back stretch: Extension and adduction and Reaching-behind-the-back stretch: extension, adduction, and internal rotation), active exercises and Codman pendulum exercises [14,15, 18,19]. All mobilizations were given in a supine position on the treatment couch. Every glide workout counted in 2 to 3 oscillations in a second for about 30sec. and providing for 5 sets [15]. 


\section{Statistical analysis:}

All statistical measures were performed using the Statistical Package for Social Science (SPSS) program version 25 for windows. Descriptive statistics and $t$-test were conducted for comparison of the mean age, weight, height and BMI between both groups. Chi-squared test was conducted for comparison of sex distribution between groups. ANOVA with repeated measures was conducted for comparison between pretreatment, post 6 sessions and post treatment measurements of ROM in each group. Post-hoc tests using the Bonferroni test were carried out for subsequent multiple comparison. Paired t test was conducted for comparison between pre and post treatment measurements of SPADI in each group. $t$-test were conducted for comparison of the percentage of change between both groups.

\section{Results}

Thirty patients of males and females aging from 40 to 60 years old with frozen shoulder participated in this study, fifteen patients in stage II (group A) and fifteen patients in stage III (group B). Comparing the general characteristics of the subjects of both groups revealed that there was no significance difference between both groups in the mean age, weight and height $(p>0.05)$. Also there was no significant difference between the both groups in the sex distribution $(p=0.43)$. Both groups received the same physical therapy program of mobilization and therapeutic exercises. Both groups were assessed pretreatment and followed up after 6 sessions ( 3 weeks) of treatment and post treatment (2 months) for ROM and pretreatment and post treatment for SPADI.

As the patients were in different stages and as the aim is to compare the effect of treatment between both stages, the percentage of change for each patient was calculated as (post-pre)/pre* 100 and the mean value was chosen for the purpose of data analysis. $t$-test was conducted for comparison of the percentage of change between both groups.

Table (1) represents that there was a significant increase in the percentage of change in shoulder flexion ROM of group A compared with that of group B ( $p=0.0001)$. As illustrated in Fig. (1). The mean \pm SD percentage of change in shoulder flexion ROM of group A was $57.56 \pm 13.54 \%$ while that in group B was $33.56 \pm 5.63 \%$ with mean difference $24 \%$, which means that the treatment was more effective in stage II than stage III.
Table (1): Comparison of percentage of change of shoulder flexion ROM post treatment between group $\mathrm{A}$ and B.

\begin{tabular}{|c|c|c|c|c|c|c|}
\hline \multirow{2}{*}{$\begin{array}{l}\text { Percentage of } \\
\text { change of } \\
\text { shoulder flexion } \\
\text { ROM }(\%)\end{array}$} & Group A & Group B & \multirow{2}{*}{ MD } & \multirow{2}{*}{$\begin{array}{c}t- \\
\text { value }\end{array}$} & \multirow{2}{*}{$\begin{array}{c}p- \\
\text { value }\end{array}$} & \multirow{2}{*}{ Sig } \\
\hline & $X \pm S D$ & $X \pm S D$ & & & & \\
\hline Post treatment & $57.56 \pm 13.54$ & $33.56 \pm 5.63$ & 24 & 6.33 & 0.0001 & S \\
\hline
\end{tabular}

$*$ : Significant at $p$-value $<0.05$.

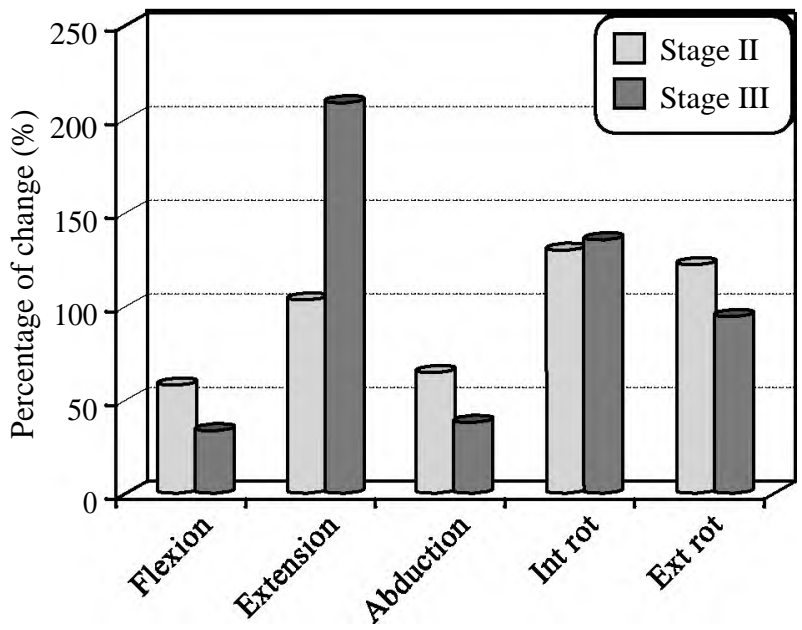

Fig. (1): Mean percentage of change of shoulder ROM at post treatment of group A and B.

Table (2) represents that there was a significant increase in the percentage of change in shoulder extension ROM of group B compared with that of group A ( $p=0.001)$. As illustrated in Fig. (1). The mean \pm SD percentage of change in shoulder extension ROM at of group A was $103.66 \pm 37.25 \%$ while that in group B was $208.88 \pm 108.76 \%$ with mean difference $-105.22 \%$ which means that the treatment was more effective in stage III than stage II.

Table (2): Comparison of percentage of change of shoulder extension ROM post treatment between group A and $\mathrm{B}$.

\begin{tabular}{|c|c|c|c|c|c|c|}
\hline \multirow{2}{*}{$\begin{array}{l}\text { Percentage of } \\
\text { change of } \\
\text { shoulder } \\
\text { extension }(\%)\end{array}$} & Group A & Group B & \multirow{2}{*}{ MD } & \multirow{2}{*}{$\begin{array}{c}t- \\
\text { value }\end{array}$} & \multirow{2}{*}{$\begin{array}{c}p- \\
\text { value }\end{array}$} & \multirow{2}{*}{ Sig } \\
\hline & $\mathrm{X} \pm \mathrm{SD}$ & $\mathrm{X} \pm \mathrm{SD}$ & & & & \\
\hline Post treatment & $\begin{array}{l}103.66 \pm \\
37.25\end{array}$ & $\begin{array}{l}208.88 \pm \\
108.76\end{array}$ & -105.22 & -3.54 & 0.001 & S \\
\hline
\end{tabular}

*: Significant at $p$-value $<0.05$.

Table (3) represents that there was a significant increase in the percentage of change in shoulder abduction ROM of group A compared with that of group B ( $p=0.0001)$. As illustrated in Fig. (1). The mean \pm SD percentage of change in shoulder abduction ROM of group A was $64.22 \pm 12.15 \%$ while that in group B was $38.25 \pm 8.03 \%$ with mean dif- 
ference $25.97 \%$ which means that the treatment was more effective in stage II than stage III.

Table (3): Comparison of percentage of change of shoulder abduction ROM at post treatment between group $\mathrm{A}$ and $\mathrm{B}$.

\begin{tabular}{|c|c|c|c|c|c|c|}
\hline \multirow{2}{*}{$\begin{array}{l}\text { Percentage of } \\
\text { change of } \\
\text { shoulder } \\
\text { abduction }(\%)\end{array}$} & Group A & Group B & \multirow{2}{*}{ MD } & \multirow{2}{*}{$\begin{array}{c}t- \\
\text { value }\end{array}$} & \multirow{2}{*}{$\begin{array}{c}p- \\
\text { value }\end{array}$} & \multirow{2}{*}{ Sig } \\
\hline & $X \pm S D$ & $\mathrm{X} \pm \mathrm{SD}$ & & & & \\
\hline Post treatment & $\begin{array}{l}64.22 \pm \\
12.15\end{array}$ & $\begin{array}{l}38.22 \pm \\
8.03\end{array}$ & 25.97 & 6.9 & 0.0001 & S \\
\hline
\end{tabular}

*: Significant at $p$-value $<0.05$

Table (4) represents that there was no significant difference in the percentage of change in shoulder internal rotation ROM between group $\mathrm{A}$ and $\mathrm{B}$ $(p=0.8)$. As illustrated in Fig. (1). The mean \pm SD percentage of change in shoulder internal rotation ROM of group A was $129.7 \pm 65.72 \%$ while that in group B was $135.66 \pm 61.93 \%$ with mean difference $-5.96 \%$ which means that no difference of the effect of treatment on both stages.

Table (4): Comparison of percentage of change of shoulder internal rotation ROM at post treatment between group $\mathrm{A}$ and $\mathrm{B}$.

\begin{tabular}{|c|c|c|c|c|c|c|}
\hline \multirow{2}{*}{$\begin{array}{l}\text { Percentage of } \\
\text { change of } \\
\text { shoulder } \\
\text { internal } \\
\text { rotation }(\%)\end{array}$} & Group A & Group B & \multirow{2}{*}{ MD } & \multirow{2}{*}{$\begin{array}{c}t- \\
\text { value }\end{array}$} & \multirow{2}{*}{$\begin{array}{c}p- \\
\text { value }\end{array}$} & \multirow{2}{*}{ Sig } \\
\hline & $\mathrm{X} \pm \mathrm{SD}$ & $\mathrm{X} \pm \mathrm{SD}$ & & & & \\
\hline Post treatment & $\begin{array}{l}129.7 \pm \\
65.72\end{array}$ & $\begin{array}{l}135.66 \pm \\
61.93\end{array}$ & -5.96 & -0.25 & 0.8 & NS \\
\hline
\end{tabular}

$*$ : Significant at $p$-value $<0.05$.

Table (5) represents that there was no significant difference in the percentage of change in shoulder external rotation ROM between group A and B $(p=0.12)$. As illustrated in Fig. (1). The mean \pm SD percentage of change in shoulder external rotation ROM of group A was $122.6 \pm 58.9 \%$ while that in group B was $94.33 \pm 35.06 \%$ with mean difference $28.27 \%$ which means that no difference of the effect of treatment on both stages.

Table (5): Comparison of percentage of change of shoulder external rotation ROM post treatment between group $\mathrm{A}$ and $\mathrm{B}$.

\begin{tabular}{|c|c|c|c|c|c|c|}
\hline \multirow{2}{*}{$\begin{array}{l}\text { Percentage of } \\
\text { change of } \\
\text { shoulder } \\
\text { external } \\
\text { rotation }(\%)\end{array}$} & Group A & Group B & \multirow{2}{*}{ MD } & \multirow{2}{*}{$\begin{array}{c}t- \\
\text { value }\end{array}$} & \multirow{2}{*}{$\begin{array}{c}p- \\
\text { value }\end{array}$} & \multirow{2}{*}{ Sig } \\
\hline & $\mathrm{X} \pm \mathrm{SD}$ & $\mathrm{X} \pm \mathrm{SD}$ & & & & \\
\hline Post treatment & $\begin{array}{l}122.6 \pm \\
58.9\end{array}$ & $\begin{array}{l}94.33 \pm \\
35.06\end{array}$ & 28.27 & 1.59 & 0.12 & NS \\
\hline
\end{tabular}

*: Significant at $p$-value $<0.05$.
Table (6) represents that there were a significant increase in the percentage of change in pain and function of group A compared with that of group B $(p=0.0001)$. As illustrated in Fig. (2). The mean \pm SD percentage of change in pain of group A was $88.82 \pm 4.37 \%$ while that in group B was $57.02 \pm$ $11.96 \%$ with mean difference $31.8 \%$. Also Fig. (2) demonstrated that the mean \pm SD percentage of change in function of group A was $89.53 \pm 4.07 \%$ while that in group B was $47.7 \pm 10.93 \%$ with mean difference $41.83 \%$ which means that the treatment was more effective in stage II than stage III.

Table (6): Comparison of percentage of change of SPADI between group A and B.

\begin{tabular}{|c|c|c|c|c|c|c|}
\hline \multirow{2}{*}{$\begin{array}{c}\text { Percentage of } \\
\text { change of } \\
\text { SPADI }(\%)\end{array}$} & Group A & Group B & \multirow{2}{*}{ MD } & \multirow{2}{*}{$\begin{array}{c}t- \\
\text { value }\end{array}$} & \multirow{2}{*}{$\begin{array}{c}p- \\
\text { value }\end{array}$} & \multirow{2}{*}{ Sig } \\
\hline & $\mathrm{X} \pm \mathrm{SD}$ & $\mathrm{X} \pm \mathrm{SD}$ & & & & \\
\hline Pain & $88.82 \pm 4.37$ & $57.02 \pm 11.96$ & 31.8 & 9.67 & 0.0001 & $S$ \\
\hline Function & $89.53 \pm 4.07$ & $47.7 \pm 10.93$ & 41.83 & 13.89 & 0.0001 & S \\
\hline
\end{tabular}

*: Significant at $p$-value $<0.05$.

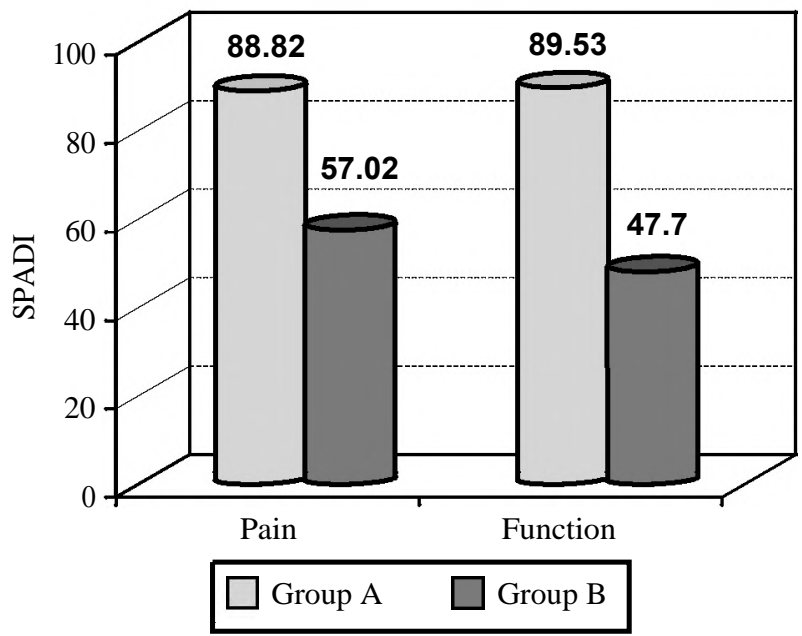

Fig. (2): Mean percentage of change of SPADI post treatment of group A and B.

\section{Discussion}

Management of adhesive capsulitis is a massive challenge and the literature highlighted various types of interventions [20]. The rehabilitation program of FS patients commonly includes exercise aimed at restoring normal shoulder kinematics and/or shoulder muscle activity [21]. Considering the pathology of frozen shoulder where in there is a contracture of joint capsule along with other periarticular structures, the effects of mobilizations were used to stretch the adhered capsule and improve the physiologic accessory movements [22] There is little evidence suggesting that physical therapy or other therapy modalities can alter disease progression [23] 
So the aim of the current study was to compare the combined effect of shoulder mobilization and therapeutic exercises on pain, range of motion (ROM), and overall shoulder functions between stage II and stage III frozen shoulder.

The finding of current study showed significant effect of mobilization and therapeutic exercises on pain and overall shoulder functions in stage II and stage III frozen shoulder with a significant increase in the percentage of change in pain and funcion of stage II compared with that of stage III. Also showed significant effect on shoulder ROM with the superiority of flexion and abduction in stage II as there was significant increase in the percentage of change in shoulder flexion and abduction ROM of group stage II compared with that of stage III. But there was no significant difference in the percentage of change in shoulder internal rotation and external ROM between stage II and stage III. Whereas there was a significant increase in the percentage of change in shoulder extension ROM of stage III compared with that of stage II. Based on that combined mobilization and therapeutic exercises are important in treatment of stage II frozen shoulder patients.

Mobilization techniques improve the normal extensibility of the shoulder capsule and stretch the tightened soft tissues to induce beneficial effects [24] (Yang et al., 2007). The results of the present study support this promise and indicate that the most beneficial effects can be achieved with combination of therapeutic exercises rather than separate one. Joint mobilization techniques are assumed to induce neurophysiologic effect which is based upon the stimulation of the peripheral mechanoreceptors and inhibition of nociceptors [25] (Mangus et al., 2002). The biomechanical effect manifests itself when forces are directed towards resistance but within the limit of subjects tolerance. The mechanical changes may include breaking up adhesions, realigning of collagen or increasing fiber glide when specific movement stress the specific part of the capsular tissue [26] (Donatelli and Wooden, 2004). Mobilization techniques are supposed to increase or maintain joint mobility by inducing rheological changes in synovial fluid, cartilage matrix and increased synovial turnover time [27] (Noel et al., 2000). Maitland's mobilization mainly consists of rhythmic oscillatory movements which stimulate the type- 2 dynamic mechanoreceptors and by this way can inhibit the type-4 nociceptive receptors and also has an effect on circulatory perfusion. Mobilization causes a reversal of the ischemia, oedema, and inflammation cycle and reduces joint effusion and relieves pain by reducing the pressure over the nerve endings [28] (Maitland, 1983). Mobilization with intense capsular stretching causes tissue remodeling refers to a physical rearrangement of the connective tissue extracellular matrix (fibers, crosslinks, and ground substance) and collagenous tissues respond to increased tensile loading by increasing the synthesis of collagen and other extracellular components [29] (Mueller and Maluf, 2002). The use of intensive mobilization techniques may help to decrease the risk of further stiffness or joint contracture progression in patients with FS [30]. The findings of this study support that promise showing better improvement in stage II FS patients.

The findings of current study agree with that of Jain and Sharma (2014) [31] who concluded that therapeutic exercises and mobilization therapy are strongly recommended for reducing pain, improving ROM and function in patients with stages II and III frozen shoulder. In addition to that present study agrees with the work of Neviaser \& Hannafin (2010) [32] who recommend stage-based treatment protocol for FS and recommended passive joint glides to increase capsular mobility and active exercises aimed at preserving motion for stage II frozen shoulder patients.

Also the findings of present study agree with and support the work of Chan et al. (2017) [33] who reported that patients in freezing stage (stage II) would benefit from gentle shoulder mobilization exercises, stretching exercises and pendulum exercises. IN addition, current study agrees with the work of Griggs et al.(2000) [34] who reported that $90 \%$ of 75 patients, classified with stage II idiopathic frozen shoulder, demonstrated good outcomes with an exercise program in a prospective functional outcome study.

The findings of current study disagree with the work of Diercks et al. (2004) [35] who found that patients in the group treated with supervised neglect achieved quicker and greater improvement in constant score than patients in the physical therapy group (passive stretching and manual mobilization) and concluded that aggressive stretching beyond a pain threshold could be detrimental, especially if applied in the early phase of the condition (Duration of symptoms: 5 months). That contrast may be due to the difference of follow-up times as their patients were followed-up for 24 months after the start of treatment.

\section{Conclusion:}

The combined effect of mobilization and therapeutic exercises capable of providing a feasible 
tool for improving shoulder pain, ROM and function in stage II frozen shoulder patients.

\section{Limitations:}

Shoulder pain and disability index was difficult to be used by my patients.

\section{Recommendations:}

Further studies are required to investigate the following for better treatment of the problem and address the study limitations:

1- How the results of the present study might be influenced by using corticosteroid injection in combination with shoulder mobilization and therapeutic exercises in stage II frozen shoulder.

2- The effect of adding home exercises program on the results of our study.

3- Effect of using objective measures for shoulder pain and disability, other than SPADI which was difficult to be used by my patients, for example pressure algometry, blood tests, and ultrasonography ... etc.

\section{Acknowledgements:}

The authors would like to thank all the patients who kindly participated in the study.

\section{References}

1- FERNÁNDEZ-DE-LAS-PEÑAS C., CLELAND J. and DOMMERHOLT J.: Manual therapy for musculoskeletal pain syndromes: An evidence- and clinical-informed approach. 1 st ed. Elsevier, Ch 30: 344-46, 2016.

2- ZUCKERMAN J. and ROKITO S.: Definition and classification of frozen shoulder: A consensus approach. J. Shoulder Elbow Surg., 83: 322-35, 2011.

3- CADOGAN A. and MOHAMMED K.D.: Shoulder pain in primary care: Frozen shoulder. J. Primary Health Care, 8: 44-51, 2016.

4- SHAMUS E.: The color atlas of physical therapy. New York: McGraw-Hill Education Medical, 2014.

5- YOON J.P., CHUNG S.W., KIM J.E., KIM H.S., LEE H.J., JEONG W.J., OH K.S., LEE D.O., SEO A. and KIM Y.: Intra-articular injection, subacromial injection, and hydrodilatation for primary frozen shoulder: A randomized clinical trial. J. Shoulder Elbow Sur., 25: 376-83, 2016.

6- NEVIASER R.J. and NEVIASER T.J.: The frozen shoulder. Diagnosis and management. Clin. Orthop. Relat. Res., 223: 59-64, 1987.

7- GEORGIANNOS D., MARKOPOULOS G., DEVETZI E. and BISBINAS I.: Adhesive Capsulitis of the Shoulder. Is there Consensus Regarding the Treatment? A Comprehensive Review. The Open Orthopaedics J., 11 (Suppl1, M2): 65-76, 2017.

8- SHERIDAN M.A. and HANNAFIN J.A.: Upper extremity: Emphasis on frozen shoulder. Orthop. Clin. North Am. 37 (4): 531-39, 2006.
9- BAL A., EKSIOGLU E., GULEC B., AYDOG E., GUR CAY E., et al.: Effectveness of corticosteroid injection in adhesive capsulitis. Clin, Rehabil, 22: 503-12, 2008.

10- VERMEULEN H.M., OBERMANN W.R., BURGER B.J., KOK G.J., ROZING P.M. and VAN DEN ENDE C.H. End-range mobilization techniques in adhesive capsulitis of the shoulder joint: A multiple-subject case report. Phys. Ther., 80: 1204-13, 2000.

11-BRUDVIG T.J., KULKARNI H. and SHAH S.: The Effect of Therapeutic Exercise and Mobilization on Patients With Shoulder Dysfunction: A Systematic Review With Meta-analysis. J. Orthop \& Sports Phys. Ther., 41 (10): 734-48, 2011

12- VERMEULEN H.M., ROZING P.M., OBERMANN W.R., LE CESSIE S. and VLIET VLIELAND T.P.: Comparison of highgrade and low-grade mobilization techniques in the management of adhesive capsulitis of the shoulder: Randomized controlled trial. Phys. Ther., 86: 355-68, 2006.

13- FAVEJEE M.M., HUISSTEDE B.M.A. and KOES B.W.: Frozen shoulder: The effectiveness of conservative and surgical interventions systematic review. Br. J. Sports Med., 45: 49-56, 2011.

14- JOHNSON A.J., GODGES J.J., ZIMMERMAN G.J. and OUNANIAN L.L.: The Effect of anterior versus posterior glide mobilization on external rotation range of motion in patients with adhesive capsulitis. J. Orthop. \& Sports Phys. Ther., 37 (3): 88-99, 2007.

15- ALI S. A. and KHAN M.: Comparison for efficacy of general exercises with and without mobilization therapy for the management of adhesive capsulitis of shoulder an interventional study. Pakistan Journal of Medical Sciences, 31 (6): 1372-76, 2015.

16- NORKIN C.C. and WHITE D.J.: Measurement of joint motion: A guide to goniometry. 5 th ed.Philadelphia: F. A. Davis Company, 72-91, 2016.

17- PINCUS T., BERGMAN M., SOKKA T., ROTH J., SWEARINGEN C. and YAZICI Y.: Visual analog scales in formats other than a 10 centimeter horizontal line to assess pain and other clinical data. J. Rheumatol., 35: 1550-8, 2008

18- HAMMER W.: Functional soft-tissue examination and treatment by manual methods. 3 rd ed. Sudbury, Mass. Jones and Bartlett Pub, Ch. 3: 125-31, 2007.

19- YANG J., JAN M., CHANG C. and LIN J.: Effectiveness of the end-range mobilization and scapular mobilization approach in a subgroup of subjects with frozen shoulder syndrome: A randomized control trial. Manual Therapy, 17 (1): 47-52, 2012.

20- CELIK D.: Comparison of the outcomes of two different exercise programs on frozen shoulder. Acta. Orthop. Traumatol. Turc., 44: 285-92, 2010.

21- KORDELLA T.: Frozen shoulder and diabetics. Diab. Fores, 55: 60-5, 2002.

22- PAUL A., RAJKUMAR J. S., PETER S., et al.: Effectiveness of sustained stretching of the inferior capsule in the management of a frozen shoulder. Clin. Orthop. Relat. Res., 472 (7): 2262-8, 2014.

23- STRUYF F. and MEEUS M.: Current evidence on physical therapy in patients with adhesive capsulitis: What are we missing? Clin. Rheumatol., 33: 593-600, 2014. 
24- YANG J.L., CHANG C.W., CHEN S.Y., WANG S.F. and LIN J.J.: Mobilization techniques in subjects with frozen shoulder syndrome: Randomized multiple treatment trial. Physical Therapy, 87: 1307-15, 2007.

25- MANGUS B.C., HOFFMAN L.A., HOFFMAN M.A. and ALTENBURGER P.: Basic principles of extremity joint mobilization using a Kaltenborn approach. J. Sport Rehabilitation, 11: 235-50, 2002.

26- DONATELLI R. and WOODEN M.J.: Orthopaedic Physical Therapy. 4 th edition. Churchill Levingstone, New York, USA, 2004.

27- NOEL G., VERBRUGGEN L.A., BARBAIX E. and DUQUET W.: Adding compression to mobilization in a rehabilitation program after knee surgery: A preliminary clinical observational study. Manual Therapy, 5: 102-7, 2000.

28- MAITLAND G.D.: Treatment of the glenohumeral joint by passive movement. Physiotherapy, 69: 3-7, 1983.

29- MUELLER M.J. and MALUF K.S.: Tissue adaptation to physical stress: A proposed "Physical Stress Theory" to guide physical therapist practice, education, and research. Physical Therapy, 82: 383-403, 2002.

30- GOYAL M., BHATTACHARJEE S. and GOYAL K.:
Combined Effect of End Range Mobilization (ERM) and Mobilization with Movement (MWM) Techniques on Range of Motion and Disability in Frozen Shoulder Patients: A Randomized Clinical Trial. J. Exercise Science and Physiotherapy, 9 (2): 74-82, 2013.

31- JAIN T.K. and SHARMA N.K.: The effectiveness of physiotherapeutic interventions in treatment of frozen shoulder/adhesive capsulitis: A systematic review. J. Back and Musculoskeletal Rehabilit, 27 (3): 247-73, 2014.

32- NEVIASER A.S. and HANNAFIN J.A.: Adhesive capsulitis: A review of current treatment. Am. J. Sports Med., 38 (11): 2346-56, 2010.

33- CHAN H., PUA P. and HOW C.: Physical therapy in the management of frozen shoulder. Singapore Med. J., 58 (12): 685-9, 2017.

34- GRIGGS S., AHN A. and GREEN A.: Idiopathic adhesive capsulitis: A prospective functional outcome study of nonoperative treatment. J. Bone Joint Surg. Am., 82: 1398-407, 2000.

35- DIERCKS R.L. and STEVENS M.: Gentle thawing of the frozen shoulder: A prospective study of supervised neglect versus intensive physical therapy in seventy-seven patients with frozen shoulder syndrome followed up for two years. J. Shoulder Elbow Surg., 13: 499-502, 2004.

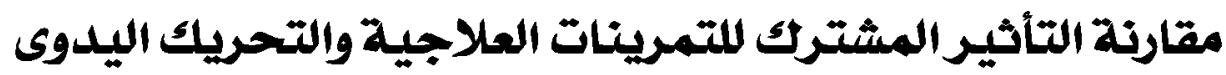



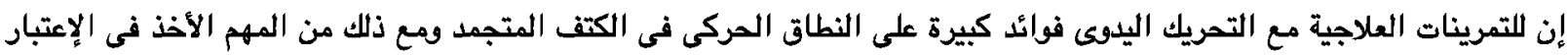



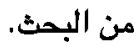

الهدف من هذه الدراسة: مقارنة التأثير المشترك للتمرينات العلاجية والتحريك اليدى على شدة الآلم والنطاق الحركى والاعاقة الوظيفية

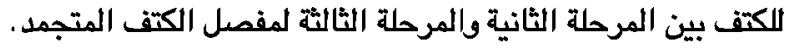

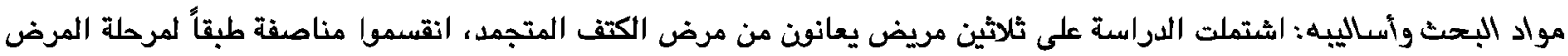

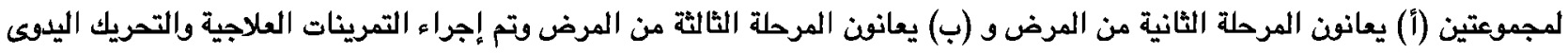

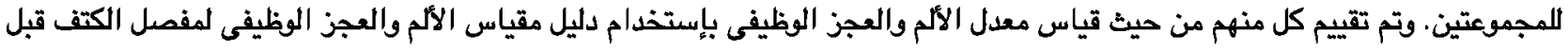

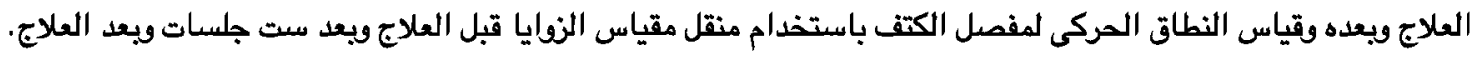

الإستتاج: للتمرينات العلاجية والتحريك اليوىى تأثير قوى ذو دلالة إحصائية على شدة الألم والاعاقة الوظيفية الكتف في المرحلة الثانية

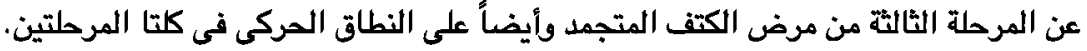

